\title{
Genetic Diversity of Salmonella enterica Strains Isolated from Sewage Samples of Different Hospitals in Bangladesh
}

\author{
Tusher-Al-Arafat ${ }^{1}$, Md. Rasel Mahmud ${ }^{1}$, Md. Tauhidul Islam Tanim¹, Md. Miraj Kobad Chowdhury², Md. \\ Mizanur Rahaman ${ }^{1}$, Sabita Rezwana Rahman ${ }^{1}$ and Md. Majibur Rahman ${ }^{1 *}$ \\ ${ }^{1}$ Department of Microbiology, University of Dhaka, Dhaka-1000, Bangladesh, ${ }^{2}$ Department of Genetic Engineering and Biotechnology, University of Dhaka, \\ Dhaka-1000, Bangladesh.
}

\begin{abstract}
The degree of salmonellosis is associated with the genetic diversity of the Salmonella enterica. Here, the genetic diversity of Salmonella enterica isolated from hospital sewage samples of Bangladesh were analyzed to elucidate the prevalence of $S$. enterica by random amplification of polymorphic DNA (RAPD) and amplified ribosomal DNA restriction analysis (ARDRA). Twenty six isolates were identified as $S$. enterica by cultural and biochemical methods as well as 16srDNA sequencing. These isolates showed two types of ARDRA and eight distinct RAPD patterns. All of these isolates possessed $i n v \mathrm{~A}$ gene. However, agf $\mathrm{A}$ and $\mathrm{fliC}$ genes were found in 21 isolates and 16 isolates respectively. All of the isolates were resistant to rifamycin but most of them were sensitive to ceftriaxone and streptomycin. The study indicated that the genetic diversity is very high among the $S$. enterica isolates of Bangladesh. Therefore, such diversity may contribute to the future outbreak of salmonellosis in Bangladesh.
\end{abstract}

Keywords: Salmonellosis, Salmonella enterica, genetic diversity, antibiotic resistance.

\section{Introduction}

Symptomatic infection caused by Salmonella spp. is called salmonellosis and thousands of people die each year due to salmonellosis worldwide ${ }^{1,2}$. In Bangladesh, salmonellosis is caused by Salmonella enterica in most cases, and can be typhoidal and nontyphoidal ${ }^{3}$. S. enterica is an important food borne pathogen prevalent worldwide and the genetic diversities of $S$. enterica have been studied in many countries ${ }^{4,5}$. These studies suggested the genetic variations in $S$. enterica and treatment options for salmonellosis varies according to the genetic diversity of $S$. enterica isolates ${ }^{6}$. Hence, it is easier to understand the pathogenesis and to develop treatment for newly emerged genetically diverged $S$. enterica pathogens whenever information on the genetic diversity of the existing strains is available. The genetic diversity of $S$. enterica isolated from Bangladesh has not been studied yet. To determine the genetic diversity, several genes were considered as candidates. Among them, 16s rDNA is widely acceptable to determine the genotype of bacteria ${ }^{7}$. Also presence of different genes like invA, fli C, and agfA were considered ${ }^{8}$. The gene invA encodes invasion protein $\mathrm{A}$, which is a marker gene for $S$. enterica. This protein is required to assist bacterial invasion to the cells of intestinal epithelium. On the contrary, $f l i \mathrm{C}$ gene encodes flagellin protein which functions to filament polymerization of bacterial flagella. And, agfA encodes fimbrin protein which is required for cell-cell adhesion ${ }^{9,10}$. In addition to these genes, random amplification of polymorphic DNA
(RAPD) technique has been utilized a short oligonucleotide primer to amplify random segment of DNA without prior knowledge of the whole genome to illustrate the genetic diversity among individuals of same species ${ }^{11}$. In present study we have studied the genetic diversity of $S$. enterica isolated from the hospital sewage samples of Bangladesh. As emerging multidrug resistant bacteria are highly prevalent in sewage samples, antimicrobial sensitivity of these strains was also studied.

\section{Materials and Methods \\ Sample Collection and Processing}

Sewage samples from four different hospitals of Bangladesh were collected in sterile McCartney bottle. The samples were filtered through sterile Grade 1 Whatman filter paper and centrifuged at $10,000 \mathrm{rpm}$ for 10 minutes to concentrate the bacterial population. These concentrates were serially diluted in normal saline and inoculated into the alkaline peptone water at $1: 10(\mathrm{v} / \mathrm{v})$ for preenrichment at $37^{\circ} \mathrm{C}$ for 6 hours. Then, the samples were transferred to selenite-cystine broth and incubated for 24 hours at $37^{\circ} \mathrm{C}$ for selective enrichment. After that, the samples were serially diluted again in normal saline and spread into xyloselysine-deoxycholate (XLD) agar media. The petridishes were incubated overnight at $37^{\circ} \mathrm{C}$ to isolate the black-centered red colonies as Salmonella spp. Individual colonies were further purified by colony purification method and then were stored as glycerol stock.

*Corresponding author:

Dr. Md. Majibur Rahman, Professor, Department of Microbiology, University of Dhaka, Dhaka-1000, Bangladesh.

Phone: 9661920-73 ext.7736. Email: majibrahman@gmail.com 


\section{Morphological and Biochemical Characterization of the Isolates}

Gram staining of the isolates was done using standard method ${ }^{12}$. solates were characterized by their response to different biochemical tests that includes Kligler Iron agar (KIA), Motility Indole Urease (MIU), Methyl-Red (MR), Voges- Proskauer (VP), Triple Sugar Iron (TSI), citrate utilization, catalase and oxidase tests.. All these biochemical tests were done according to the standard procedure and the results were observed after incubation at $37^{\circ} \mathrm{C}$ for $24-48$ hours $^{13}$. Antibiogram of the isolates were done by standard Kirby-Bauer disc diffusion method ${ }^{14}$ using 15 antibiotics including amoxicillin (30 1/4g), ampicillin (30 1/4g), azithromycin $\left(15 \frac{1}{4} \mathrm{~g}\right)$, cefixime $\left(5 \frac{1}{4} \mathrm{~g}\right)$, cefotaxime $(301 / 4 \mathrm{~g})$, ceftriaxone $(301 / 4 \mathrm{~g})$, chloramphenicol $(301 / 4 \mathrm{~g})$, ciprofloxacin $(5$ $1 / 4 \mathrm{~g})$, co-trimoxazole $(301 / 4 \mathrm{~g})$, erythromycin $\left(15^{1 / 4 \mathrm{~g}}\right)$, kanamycin (30 1/4g), nalidixic acid (30 1/4g), rifamycin ( $51 / 4 \mathrm{~g})$, streptomycin $\left(10 \frac{1 / 4}{\mathrm{~g}}\right)$, and tetracycline $(30 \mathrm{1} / \mathrm{gg})$. Antibiotic susceptibility was deduced according to the standard guidelines ${ }^{15}$.

\section{Molecular Characterization of the Isolates}

DNA was extracted and purified from individual isolates using standard phenol-chloroform-isoamyl alcohol method ${ }^{16}$. The quality and quantity of the purified DNA was measured using NanoDrop ${ }^{\mathrm{TM}}$ spectrophotometer and the working concentration was adjusted to $50 \mathrm{ng} /$ ?1. For molecular characterization, PCR was performed using the primers as given in Table 1. For random amplification of polymorphic DNA (RAPD), the purified DNA was amplified using the RAPD primer (52-GCGATCCCCA-32 ). For all PCR except RAPD, each reaction was set up consisting 12.5 ? 1 of 2X Taq PCR Master Mix (Qiagen, USA), 1 ? 1 of 10 pmol/?1 of each forward and reverse primers, 4 ? 1 of template DNA and 6.5 ? 1 of nuclease free water. The thermocycling conditions were $95^{\circ} \mathrm{C}$ for 1 minute and subsequently 35 cycles at $95^{\circ} \mathrm{C}$ for 30 seconds followed by 30 seconds at annealing temperature (Table 1), and $72^{\circ} \mathrm{C}$ for 30 seconds, with a final extension at $72^{\circ} \mathrm{C}$ for 4 minutes. For RAPD, primer concentration was $20 \mathrm{pmol} / ? 1$ and the thermocycling conditions were $94^{\circ} \mathrm{C}$ for 5 minutes, followed by 35 cycles at $94^{\circ} \mathrm{C}$ for 1 minute, $39^{\circ} \mathrm{C}$ for 1 minute and $72^{\circ} \mathrm{C}$ for 2 minutes, with a final extension at $72^{\circ} \mathrm{C}$ for 10 minutes. A template-free negative control was also used during PCR. The PCR product was visualized by electrophoresis in $1.5 \%$ agarose gel stained with ethidium bromide under UV- transilluminator and photomicrograph was taken in gel documentation system. For 16srDNA sequencing, PCR products were sent to First Base Malaysia and the sequences were processed using Sequencer v5.4. Sequences were further analyzed using MEGA v6.0 and NCBI tools. For Amplified rDNA restriction analysis (ARDRA) of the 16sr DNA, the PCR products were digested overnight with AluI (Thermo Fisher Scientific, USA) and resolved in a $1.5 \%$ agarose gel followed by visualization under UV-transilluminator after staining with ethidium bromide.

\section{Results and Discussion}

We have successfully isolated 26 strains of Salmonella enterica confirmed by morphological, biochemical and molecular characterization. In XLD agar, all of these strains produced blackcentered red colonies. All these strains were Gram negative small, rod shaped bacteria arranged in single or paired which correspondent with the morphological characteristics of $S$. enterica as described before. All of these strains were catalase positive and fermentative but non-lactose fermenting bacteria. These strains were able to utilize citrate as energy source, produce hydrogen sulfide and were negative for oxidase, urease, tryptophanase activities and acetoin production. All these biochemical features suggested that these strains are in fact $S$. enterica ${ }^{13}$.

For further confirmation, molecular characterization was done to evaluate the presence of three genes, invA (invasion protein A), fliC (flagellin protein), and agfA (fimbrin protein) genes. All of these strains were positive for $i n v \mathrm{~A}$, which is unique to $S$. enterica ${ }^{17}$. However, 16 strains were positive for $f l i \mathrm{C}$ gene and 21 strains were positive for agfA gene (Figure 1). We have also amplified partial 16sr DNA gene of these isolates and did ARDRA analysis by digesting the $16 \mathrm{~s}$ rDNA PCR product with AluI (Figure 2). The ARDRA patterns of the digest indicated the presence of two groups of $S$. enterica. 18 isolates belonged to ARDRA group 1 and the rest 8 strains belonged to ARDRA group 2. To further confirm these groups, we sequenced the 16s rDNA of these isolates and analyzed the sequence at NCBI basic local alignment search tool. We have found that the ARDRA group 1 belongs to S. enterica serovar Typhimurium and the ARDRA group 2 belongs to the $S$. enterica serovar Typhi.

Table 1. List of the primers used in this study.

\begin{tabular}{|c|c|c|c|c|}
\hline Gene & Primer & Sequence (52 to 32 ) & Annealing Temperature $\left({ }^{\circ} \mathrm{C}\right)$ & Amplicon Size (bp) \\
\hline \multirow[t]{2}{*}{$\overline{i n v \mathrm{~A}}$} & Forward & GTGAAATTATCGCCACGTTCGGGCAA & 64 & 284 \\
\hline & Reverse & TCATCGCACCGTCAAAGGAACC & & \\
\hline \multirow[t]{2}{*}{$f l i C$} & Forward & CGGTGTTGCCCAGGTTGGTAAT & 56 & 620 \\
\hline & Reverse & ACTCTTGCTGGCGGTGCGACTT & & \\
\hline \multirow[t]{2}{*}{$\operatorname{agfA}$} & Forward & TCCACAATGGGGCGGCGGCG & 58 & 350 \\
\hline & Reverse & CCTGACGCACCATTACGCTG & & \\
\hline \multirow{2}{*}{ 16s rDNA } & Forward & AGAGTTTGATCMTGGCTCAG & 55 & 1466 \\
\hline & Reverse & CGGTTACCTTGTTACGACTT & & \\
\hline
\end{tabular}




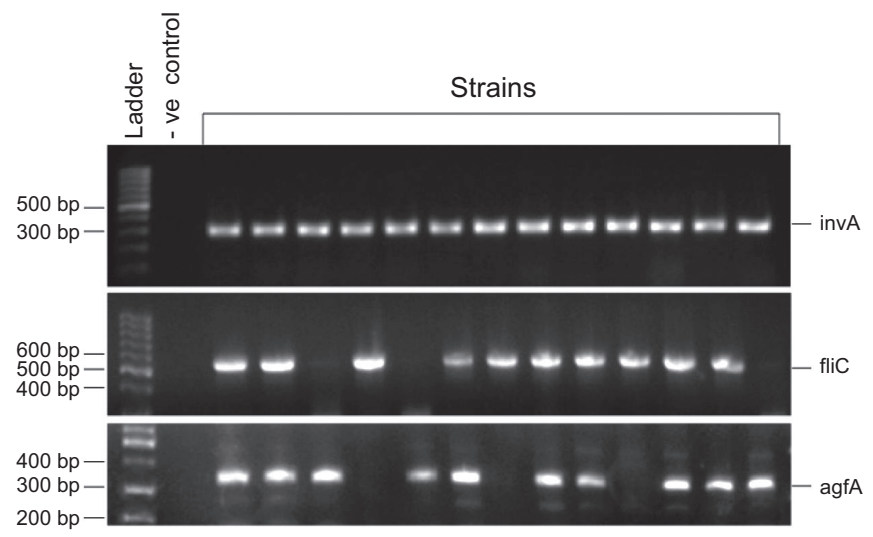

Figure 1. Presence of invA, fliC, and agfA genes in the isolates. All the isolates were invA positive indicative of Salmonella enterica.

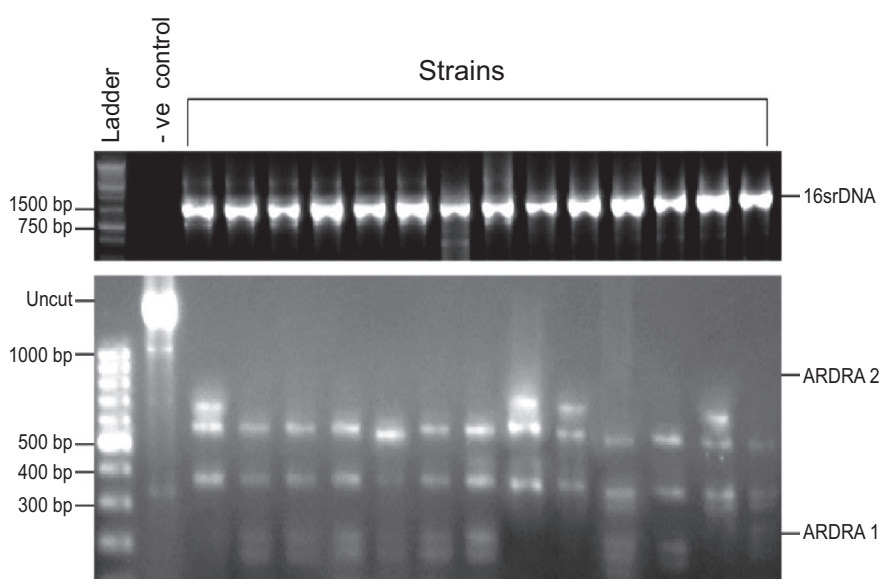

Figure 2. Amplification of $16 \mathrm{~s}$ rDNA and ARDRA of the isolated strains. Two different ARDRA patterns were observed among the strains.

To elucidate the genetic diversity of the isolates, RAPD was done (Figure 3). The RAPD pattern of the isolates revealed that there exist at least eight genetically diverse groups of $S$. enterica bacteria. Among them, group A, B, and E consists of five isolates each; 4 isolates in group F; 3 isolates in group D; and 2 isolates in group $\mathrm{H}$. Group $\mathrm{C}$ and $\mathrm{G}$ consists of only one isolate each.

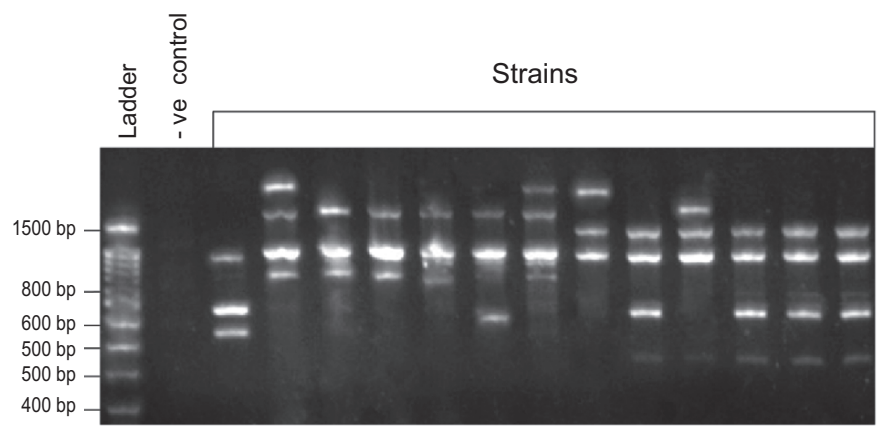

Figure 3. RAPD analysis of the isolated strains. Eight different RAPD patterns were observed among the strains.
These data indicated that the genetic diversity of the isolates were very high. When dendrogram of these RAPD patterns was constructed using Jaccard similarity co-efficient ${ }^{18}$, it was observed that Group A, B, C, and D clustered together while Group E, F, and G were closely related. However, S. enterica isolates of Group $\mathrm{H}$ were distinctly diverse from all the other $S$. enterica isolates (Figure 4).

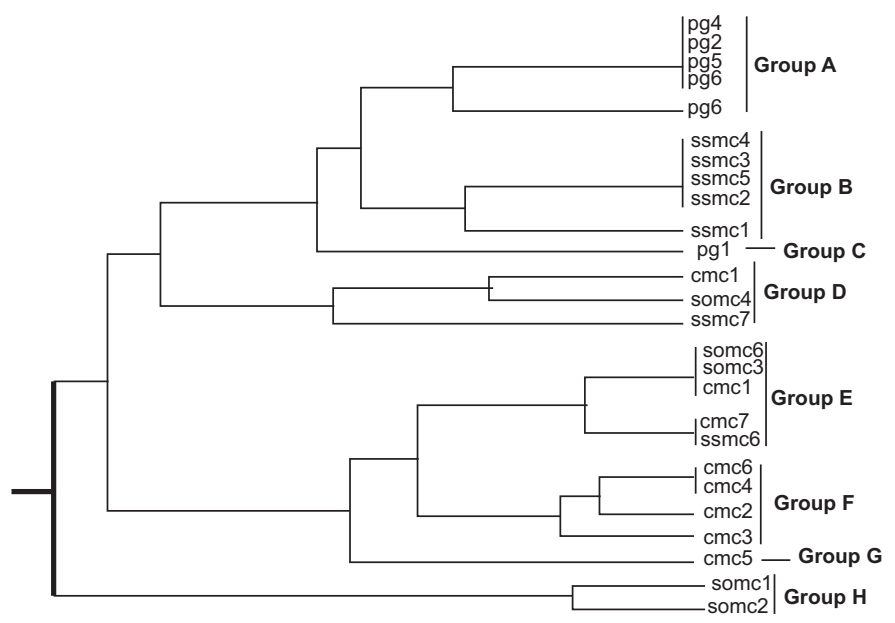

Figure 4. A dendrogram constructed with the RAPD patterns of the isolates using Jaccard similarity coefficient.

Antimicrobial susceptibility analysis revealed that all of the $S$. enterica isolates were resistant to rifamycin, as well as none of the isolates were susceptible to amoxicillin (30 1/4 g), cotrimoxazole $\left(30 \frac{1}{4} \mathrm{~g}\right)$, erythromycin $\left(15 \frac{1}{4} \mathrm{~g}\right)$, and nalidixic acid (30 $1 / 4 \mathrm{~g}$ ) (Table 2). However, more than $50 \%$ of the isolates were susceptible to ampicillin $(301 / 4 \mathrm{~g})$, azithromycin $\left(15 \frac{1}{4} \mathrm{~g}\right)$, cefixime $\left(5 \frac{1}{4} \mathrm{~g}\right)$, cefotaxime $(30 \mathrm{l} / 4 \mathrm{~g})$, ceftriaxone $(30 \mathrm{l} / \mathrm{g})$, kanamycin $\left(30 \frac{1}{4} \mathrm{~g}\right)$, streptomycin $\left(10 \frac{1}{4} \mathrm{~g}\right)$, and tetracycline $\left(30 \frac{1}{4} \mathrm{~g}\right)$.

Table 2. Antibiotic resistance of the isolates.

\begin{tabular}{lccc}
\hline Antimicrobial Agents & \multicolumn{3}{c}{$\%$ of total no of isolates } \\
(disc content) & Resistant & Intermediate & Sensitive \\
\hline Amoxicillin $(30 \mu \mathrm{g})$ & 76 & 24 & 0 \\
Ampicillin $(30 \mu \mathrm{g})$ & 44 & 0 & 56 \\
Azithromycin $(15 \mu \mathrm{g})$ & 20 & 0 & 80 \\
Cefixime $(5 \mu \mathrm{g})$ & 28 & 12 & 60 \\
Cefotaxime $(30 \mu \mathrm{g})$ & 32 & 0 & 68 \\
Ceftriaxone $(30 \mu \mathrm{g})$ & 16 & 2 & 76 \\
Chloramphenicol $(30 \mu \mathrm{g})$ & 32 & 20 & 48 \\
Ciprofloxacin $(5 \mu \mathrm{g})$ & 52 & 8 & 40 \\
Co-trimoxazole $(30 \mu \mathrm{g})$ & 96 & 4 & 0 \\
Erythromycin $(15 \mu \mathrm{g})$ & 72 & 28 & 0 \\
Kanamycin $(30 \mu \mathrm{g})$ & 24 & 0 & 76 \\
Nalidixic acid $(30 \mu \mathrm{g})$ & 72 & 28 & 0 \\
Rifamycin $(5 \mu \mathrm{g})$ & 100 & 0 & 0 \\
Streptomycin $(10 \mu \mathrm{g})$ & 16 & 12 & 72 \\
Tetracycline $(30 \mu \mathrm{g})$ & 40 & 0 & 60 \\
\hline
\end{tabular}




\section{Conclusion}

Bangladesh is a developing country with inadequate medical facilities. Thereby, outbreak of infectious diseases from emerging pathogens pose critical threats to the healthcare system as well as to public health. Since genetic diversity of current pathogens forecast the pathogenesis of future strains ${ }^{5}$, S. enterica isolates of Bangladesh were studied here to elucidate their divergence. We have concluded that RAPD is better in explaining the diversity than ARDRA. We have also found that invA, agfA, and fli $\mathrm{C}$ genes are present in most isolates and these isolates were resistant to rifamycin and co-trimoxazole. In conclusion, we have successfully deduced the genetic diversity of 26 rifamycinresistant $S$. enterica sewage isolates.

\section{Conflict of Interest}

The authors declare no conflict of interest.

\section{Acknowledgement}

We gratefully acknowledge the financial assistance made by the Ministry of Education, Govt. of the People's Republic of Bangladesh and University Grants Commission to carry out this project.

\section{References}

1. Majowicz SE, Musto J, Scallan E, Angulo FJ, Kirk M, O’Brien SJ, Jones TF, Fazil A and Hoekstra RM. 2010. The global burden of nontyphoidal Salmonella gastroenteritis. Clin. Iinfect. Diseases. 50: 882-9.

2. Vugia DJ, Samuel M, Farley MM, Marcus R, Shiferaw B, Shallow S, Smith K and Angulo FJ. 2004. Invasive Salmonella infections in the United States, FoodNet, 1996-1999: incidence, serotype distribution, and outcome. Clin. Infect. Diseases. 38(3): S149-56.

3. Darton TC et al. 2017. The STRATAA study protocol: a programme to assess the burden of enteric fever in Bangladesh, Malawi and Nepal using prospective population census, passive surveillance, serological studies and healthcare utilisation surveys. BMJ Open. 7: e 016283.

4. Li Q, Wang X, Yin K, Hu Y, Xu H, Xie X, Xu L, Fei X, Chen X and Jiao X. 2018. Genetic analysis and CRISPR typing of Salmonella enterica serovar Enteritidis from different sources revealed potential transmission from poultry and pig to human. Int. J. Food Microbiol. 266: 119-125.

5. Thong KL, Goh YL, Radu S, Noorzaleha S, Yasin R, Koh YT, Lim VK, Rusul G and Puthucheary SD. 2002. Genetic diversity of clinical and environmental strains of Salmonella enterica serotype Weltevreden isolated in Malaysia. J. Clin. Microbiol. 40: 2498-503.
6. Chiu CH, Su LH and Chu C. 2004. Salmonella enterica serotype Choleraesuis: epidemiology, pathogenesis, clinical disease, and treatment. Clin. Microbiol. Rev. 17: 311-22.

7. Foley SL, White DG, McDermott PF, Walker RD, Rhodes B, FedorkaCray PJ, Simjee S and Zhao S. 2006. Comparison of subtyping methods for differentiating Salmonella enterica serovar Typhimurium isolates obtained from food animal sources. J. Clin. Microbiol. 44: 3569-77.

8. Huang KH, Hsu BM, Chou MY, Tsai HL, Kao PM, Wang HJ, Hsiao HY, Su MJ and Huang YL. 2014. Application of molecular biological techniques to analyze Salmonella seasonal distribution in stream water. FEMS mMicrobiol. Lett. 352: 87-96.

9. Salehi TZ, Tadjbakhsh H, Atashparvar N, Nadalian MG and Mahzounieh MR. 2007. Detection and identification of Salmonella Typhimurium in bovine diarrhoeic fecal samples by immunomagnetic separation and multiplex PCR assay. Zoono. Pub. health. 54: 231-6.

10. Cogan TA, Jorgensen F, Lappin-Scott HM, Benson CE, Woodward MJ and Humphrey TJ. 2004. Flagella and curli fimbriae are important for the growth of Salmonella enterica serovars in hen eggs. Microbiol. 150: 1063-71.

11. Nath G, Maurya P and Gulati AK. 2010. ERIC PCR and RAPD based fingerprinting of Salmonella Typhi strains isolated over a period of two decades. Infect. Genetc. Evol. 10: 530-6.

12. Kaplan ML and Kaplan L. 1933. The Gram Stain and Differential Staining. J. Bacteriol. 25: 309-21.

13. Olsen JE, Brown DJ, Baggesen DL and Bisgaard M. 1992. Biochemical and molecular characterization of Salmonella enterica serovar berta, and comparison of methods for typing. Epidemiol. Infect. 108: 243-60.

14. Biemer JJ. 1973. Antimicrobial susceptibility testing by the Kirby-Bauer disc diffusion method. Annals Clin. Lab. Sci. 3: 135-40.

15. Dalyan Cilo B, Topac T, Agca H, Saglam S, Efe K and Ener B. 2018. Comparison of Clinical Laboratory Standards Institute (CLSI) and European Committee on Antimicrobial Susceptibility Testing (EUCAST) broth microdilution methods for determining the susceptibility. Mikrobiyol Bul. 52: 35-48.

16. Ling JM, Lo NW, Ho YM, Kam KM, Hoa NT, Phi LT and Cheng AF. 2000. Molecular methods for the epidemiological typing of Salmonella enterica serotype Typhi from Hong Kong and Vietnam. J. Clin. Microbiol. 38: $292-300$.

17. Bai J, Trinetta V, Shi X, Noll LW, Magossi G, Zheng W, Porter EP, Cernicchiaro N, Renter DG and Nagaraja TG. 2018. A multiplex realtime PCR assay, based on invA and pagC genes, for the detection and quantification of Salmonella enterica from cattle lymph nodes. $J$. Microbiol. Meth. 148: 110-116.

18. Martinez N, Mendoza MC, Guerra B, Gonzalez-Hevia MA and Rodicio MR. 2005. Genetic basis of antimicrobial drug resistance in clinical isolates of Salmonella enterica serotype Hadar from a Spanish region. Microbial Drug Resist. 11: 185-93. 